\title{
Multicriteria HR Allocation Based on Hesitant Fuzzy Sets and Possibilistic Programming
}

\section{Zoran Ciric, Dragan Stojic, Otilija Sedlak}

Faculty of Economics Subotica, Segedinski put 9-11, 24000 Subotica, Serbia

e-mail: zoran.ciric@ef.uns.ac.rs, stojicd@ef.uns.ac.rs, otilijas@ef.uns.ac.rs

\begin{abstract}
We focus in this paper on posing and solving a problem of human resource management, namely allocating $n$ people into $m$ groups, such that each group satisfies minimal quality conditions. Each individual is evaluated for every quality by the expert who grades them using hesitant fuzzy numbers, thus enabling a more realistic mark giving method by avoiding artificially imposed accuracy. We compare results with crisp models of Lin and Gen and discuss the significance of fuzzy methodology.
\end{abstract}

Keywords: hesitant fuzzy sets; multicriteria optimization; possibilistic programming

\section{Introduction}

Just as in many other areas, project management makes use of mathematical modeling in cases such as setting strategic goals, formulation of strategies, selection of human resources and realization of the chosen strategy and control. Criteria and restrictions of alternatives are also encompassed in the space of uncertainty and indeterminacy.

Resource Allocation Problem (RAP) is the process of allocating resources among the various projects or business units for maximization of profit or minimization of cost [10]. The process of the RAP is focused on finding an optimal allocation of limited resources to a certain number of tasks while controlling for the given resource constraint. Resource may be any entity used to accomplish a goal, e.g. a person, an asset, material, etc. This paper deals with human resource allocation. We start from a set of individuals who were tested for certain qualities by the experts. The novelty lies in the fact that marks given by the experts need not to be exact numbers, but qualitative values, such as: absolutely true, highly true, moderately true, etc. Furthermore, if experts do have certain hesitations it will be allowed to choose more than one 'mark', thus avoiding to be artificially precise. Methodology which allows us to model indeterminacy is fuzzy sets theory, which is particularly well designed for dealing with non-probabilistic uncertainties. Following the work of Saaty et al. [20] we observe marketing sector vacancies. 
We expand their work in two directions: expanding the grading system and, indirectly, the coefficients of model constraints which become fuzzy. On the other hand, we allow each candidate to be placed at the position best suited for his qualities, which is not necessarily the position he/she would apply for in the first place.

Chapter two focuses on literature review, both of human resources allocation and hesitant fuzzy sets. Chapter three presents the data and variables. We pose the model and perform an in-depth analysis and construction of constraints' coefficients. LINDO software is used for solving binary variables problems. Results are presented and differences between results of similar studies are pointed out. Finally, the last chapter concludes and the guidelines for future research are given.

\section{Literature Review}

We begin with the review of papers which inspired us the most, dealing with human resources allocation. Due to the considerable amount of subjectivity involved in hiring people, it is helpful to have prioritization techniques to deal with intangibles and make the process more objective, Saaty [18] and Saaty et al. [19]. They propose Analytic Hierarchy Process (AHP), and linear programming to rate and derive the best combination of people assigned to jobs [24] such as Rezaei et al. [15].

Filho et al. [6] uses the Constraint Satisfaction Problem approach to solve human resource allocation problems in cooperative health services. They proposed a new tool for planning human resources utilization in hospital plants, i.e. health units. They used simulations for measuring the performance of the proposed heuristics. Another contribution of this work was the mathematical modeling of the unary, multiple, numeric and implicit constraints.

Ballesteros-Pérez et al. [2] described a new application to key sociometrical concepts for the selection of workers within organizations in area of project development, in order to assure the achieving of the highest possible overall work efficiency from the viewpoint of social interaction.

Silva and Costa [21] focused on software development projects and presented a methodology based on dynamic programming for assigning human resources to the observed projects [24]. The methodology takes into account the complexity of each project and the existing capabilities of staff and the skills required for the project. A simulation is used to demonstrate the decision model.

The concept of Hesitant Fuzzy Sets (HFS) is a new one, dating back to Torra [23]. HFS are a generalization of intuitionistic fuzzy sets of Atanassov and Gargov [1] who allowed each fuzzy membership function to have a degree of indeterminacy. 
Torra defines a HFS through a function that returns a set of membership values for each element in the domain. The applications of HFS followed various directions, mostly in generalization of the existing results dealing with (ordinary) fuzzy sets. Rodríguez et al. [17] focused on group decision making (GDM) and hesitant situations that could arise from multiple opinions. They have shown how to generate comparative linguistic expressions by using a context-free grammar. Rodríguez et al. [16] extended context-free grammar to that defined in Rodríguez et al. [17], and further expanded the topics in GDM in terms of expressing and modeling doubt between different linguistic terms, requiring richer expressions to express the experts' knowledge more accurately.

On the other line of reasoning, but also tackling the decision making processes, $\mathrm{Xia}$ and $\mathrm{Xu}$ [25] presented an extensive study on hesitant fuzzy information aggregation techniques and their application in decision making with anonymity. They have developed certain hesitant fuzzy operational rules based on the interconnection between the hesitant fuzzy set and the intuitionistic fuzzy set, as well as a series of aggregation operators for dealing with various situations, and risk. Portik and Pokoradi have applied the fuzzy rule based risk assessment and the authors use it in the decision making process [14].

\section{Methodology and Model Explanation}

In this chapter we shall present in detail the proposed methodology and provide the readers with the model for human resources allocation to different positions in marketing sector. When evaluating candidates, HR management is confronted with a significant number of tradeoffs over a diverse range of criteria.

Multiple-objective optimization problems have gained momentum in researchers' community with various backgrounds since early 1960. In the realm of multiobjective optimization problem, multiobjective functions are optimized simultaneously. Therefore, there does not necessarily exist a solution that is best with respect to all objectives due to the incommensurability and confliction among objectives. A solution may be the best in one objective but underperforming in another. The so-called Pareto optimal solutions are a set of solutions for the multiple-objective case which cannot simply be compared with each other, i.e. no improvement is possible in any objective function without sacrificing at least one of the other objective functions.

Fuzzy mathematical programming (FMP) was developed in order to adequately solve optimization problems which poses non stochastic indeterminacies. Inuiguchi [7] classifies FMP in three categories based on the types of indeterminacies: 1) FMP with ambiguities, also known as flexible programming, developed by Bellman and Zadeh [3], allows fuzzy preferences for the decision maker. 2) FMP with vagueness deals with fuzzy coefficients in constraints and 
goals. Dubois and Prade [4] were the first researchers who investigated systems of linear equations with fuzzy coefficients and suggested possible applications of fuzzy mathematical programming. Dubois [5] observed fuzzy coefficients as possibilistic distributions of coefficient values, hence the name possibilistic programming for the second type of FMP. Following the early work of Dubois, we shall apply possibility theory in our linear model. Finally, third type, robust programming combines fuzzy coefficients and ambiguous preferences of the decision makers. Negoita et al. [12] were the first to formulate such a linear programming problem.

Managing and modeling of uncertainty by different forms of information, used by experts to provide their preferences, can be done in various ways, including utility vectors, fuzzy preference relations, linguistic variables, interval values, multiplicative preference relations, hesitant fuzzy sets.

Hesitant fuzzy sets are a generalization of 'ordinary' fuzzy sets and will be used in possibilistic programming. For every element $x$ from the domain $X$, membership function of a HFS A is given by $h(x)=A_{x}$, where $A_{x}$ is any (finite) subset of $[0,1]$. Suppose that the experts deciding on candidate's communication skills should choose a grade from the set of linguistic descriptions, $\mathrm{L}=\{$ none, very low, low, medium, high, very high, absolute $\}$. Of course, if unsure of the exact grade, an expert has a possibility to opt for two or more grades ${ }^{1}$. Grades can be naturally ordered, and modeled by fuzzy sets, as shown in Figure 1.

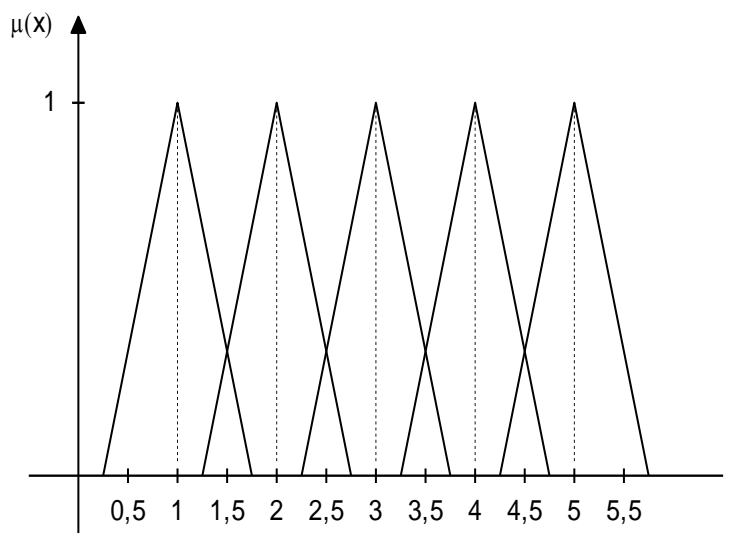

Figure 1

Choosing more than one grade would result in 'merging' the graphs of chosen grades into one convex fuzzy set. It is done by means of envelope which is a linguistic interval whose limits are minimal and maximal linguistic term, as shown in Figure 2.

\footnotetext{
${ }^{1}$ Choosing all options is equivalent to total absence of knowledge.
} 


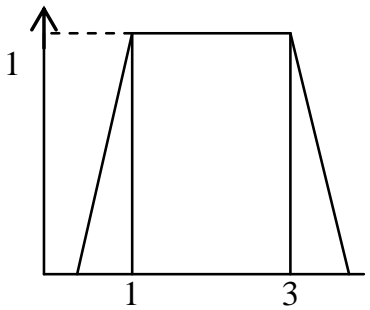

Figure 2

We observe only symmetrical marks, bounded with linear functions, though different methods of forming asymmetrical functions exist and can be found in Inuiguchi et al. [8]. We also refer an interested reader to Klir and Yuan [9] for any comprehensive and in-depth reading on fuzzy sets and fuzzy logic, such as Nagy et al. ([11]) and Takacs [22].

\subsection{The Model}

Let us observe a company 'Comp' consisting of S sectors (Manufacturing, Marketing, R\&D, etc.) Each sector consists of up to P positions (e.g. Marketing sector embodies marketing vice president, marketing assistant, customer service representative, shipping clerk, etc.), i.e. $P=\max P_{i}$, where $P_{i}$ is the number of positions in sector $i, i=1,2, \ldots S$. Each position employs up to $K$ employees, where $\mathrm{K}$ being $\operatorname{maxK}_{\mathrm{ij}}$, and $\mathrm{K}_{\mathrm{ij}}$ is the number of employees on the position $\mathrm{j}$ of the sector $i$ (e.g. there are two positions for marketing VP, 3 for marketing assistant, 6 for customer service representative, 2 for shipping clerk, etc.)

There is a total of $N$ candidates, each being tested for $\mathrm{C}$ characteristics, regardless of the position he/she apply for. The program chooses based on the test results the position one is suited best for, and that doesn't necessarily mean is the position one applied for. Characteristics include experience, organizational skills, dependability, computer knowledge, contacts, formal education, etc. These characteristics are measured by both numerical values and experts' opinions in terms of hesitant fuzzy sets, and their systematization with graphical expressions is given below:

Experience is divided into three broad intensity groups: high (corresponds to $15+$ years of experience), medium (6-15 years), and low (up to 5 years). For each broad group experts are asked to grade the applicant in terms how satisfactory (in terms of Figures 1 and 2) his actual achievements are, being in a certain intensity group. Similar reasoning goes for following characteristics: quality contacts and leadership, which are also divided into high, medium, and low, with further subdivisions by the experts (Figure 3). Organizational and computer skills, as well as dependability are solely divided into broad groups, without additional experts' 
opinion. Finally, education is divided into $\mathrm{PhD}, \mathrm{MSc}, \mathrm{BSc}$, and secondary, while the experts give opinion on the quality of the school attended, thus allowing for slight differences within the same educational level.

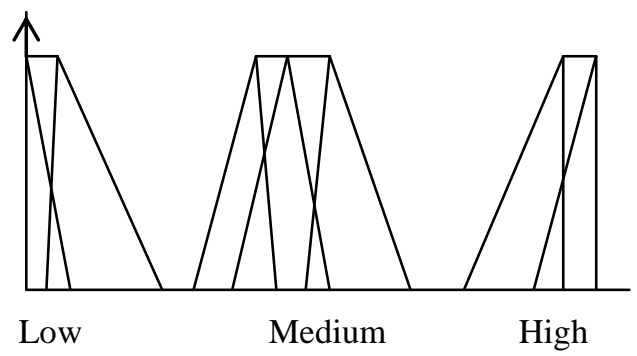

Figure 3

Let us denote by $x_{i j k}$ a binary variable which has a value 1 if the candidate $k$, $k=1 \ldots N$ is chosen for the position $i, i=1 \ldots P$ in sector $j, j=1 \ldots S$, otherwise, $x_{i j k}$ has a value 0 . Natural constraints imposed on $x$ 's are following:

$\sum_{i}^{P} \sum_{j}^{S} \sum_{k}^{N} x_{i j k}=1$, for every $k=1 \ldots N$.

One candidate can be employed at exactly one position.

$$
\sum_{i}^{P} \sum_{j}^{S} \sum_{k}^{N} x_{i j k} \leq N
$$

Total number of candidates exceeds number of positions.

Each sector is choosing candidates in order to maximize it's manpower:

$$
\sum_{i}^{P} \sum_{j}^{S} \sum_{k}^{N} c_{i j k} x_{i j k}
$$

Coefficients $c_{i j k}$ in the linear expression (3) are fuzzy numbers of triangular, or trapezoidal shape and are obtained through summation of grades for each position.

Analytical and graphical expression of a trapezoidal number $A=(a, b, \alpha, \beta)$ is given by following membership function and in Figure 4:

$\mu_{A}(x)=\left\{\begin{array}{rr}1-\frac{a-x}{\alpha}, & a-\alpha \leq x \leq \alpha \\ 1 & , a \leq x \leq b, \\ 1-\frac{x-b}{\beta}, & b \leq x \leq b+\beta\end{array}\right.$ 


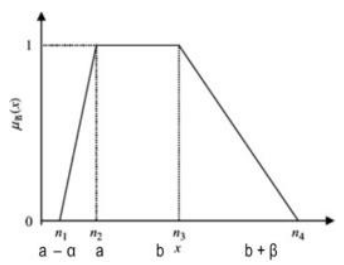

Figure 4

The linear combination of fuzzy trapezoidal numbers, which is present as a constraint expression as well as a goal function, is again a number of the same shape. If we denote by $\left(a_{i j k}, b_{i j k}, \alpha_{i j k}, \beta_{i j k}\right)$ coefficient $c_{i j k}$, the total manpower TM, defined at (3) is given by:

$$
\left(\sum_{i, j, k} a_{i j k} x_{i j k}, \sum_{i, j, k} b_{i j k} x_{i j k}, \sum_{i, j, k} \alpha_{i j k} x_{i j k}, \sum_{i, j, k} \beta_{i j k} x_{i j k}\right)=(A(x), B(x), \alpha(x), \beta(x))
$$

The possibilistic linear function is not uniquely determined, therefore its maximization, as well as constraints of the form $(A(x), B(x), \alpha(x), \beta(x)) \geq M$ may not be completely meaningful. For overcoming this problem we introduce a socalled 'fuzzy inequality', $\rho(A, B)$, where $A$ and $B$ are two fuzzy sets. If the possiblistic distribution $\mu_{A}$ of a possibilistic variable $\alpha$, the measurements of possibility and necessity of an event that $\alpha$ belongs to the set $B$ ([5]):

$\operatorname{Poss}_{A}(B)=\sup _{x} \min \left(\mu_{A}(x), \mu_{B}(x)\right)$

$\operatorname{Nes}_{A}(B)=\inf _{x} \max \left(1-\mu_{A}(x), \mu_{B}(x)\right)$,

where $\mu_{B}$ is a membership function of a set $B . \operatorname{Poss}_{A}(B)$ estimates the level up to which it is possible that possibilistic variable $\alpha$ belongs to the set $B$. on the other side, the expression $\operatorname{Nes}_{A}(B)$ measures the level of necessity up to which is certain that $\alpha$ belongs to the set $B$. Let $\alpha$ be a possibilistic variable and $B=(-\infty, g]$, a crisp set. One could easily obtain the following: $\operatorname{Pos}(\alpha \leq g)=\sup \left\{\mu_{A}(x) \mid x \leq g\right\}$ and $\operatorname{Nes}(\alpha \leq g)=1-\sup \left\{\mu_{A}(x) \mid x>g\right\}$, which is exhibited in Figure 5. Similarly, for $B$ $=[g,+\infty)$ we obtain following equations presented in Figure 6:

$\operatorname{Pos}(\alpha \geq g)=\sup \left\{\mu_{A}(x) \mid x \geq g\right\}$ and $N e s(\alpha \geq g)=1-\sup \left\{\mu_{A}(x) \mid x<g\right\}$.
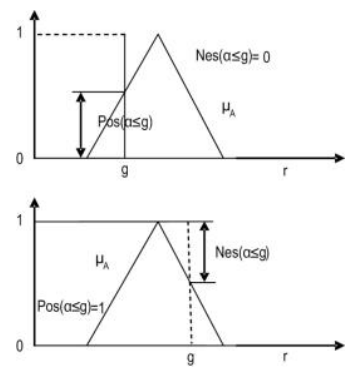

Figure 5 


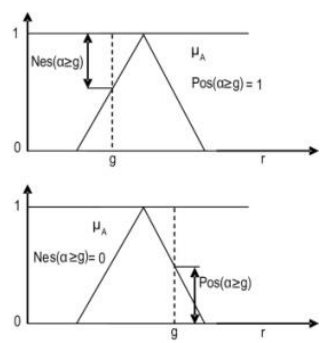

Figure 6

The constraints on the number of people in each position are given by:

$\sum_{i, j} x_{i j k}=p_{i j}$, where $i$ is the number of sectors, $i=1 \ldots S$ and $\mathrm{j}$ is the number of positions in each sector, $j=1 \ldots P$.

Maximization of the total human potential of the company is done by maximizing the right spread of the possibilistic distribution, allowing for the best possible marks to be incorporated in the optimal team:

Maximize $\sum_{i, j, k}\left(\beta_{i j k}+b_{i j k}\right) x_{i j k}$

One of the possible restrictions is a funding restriction. Each employee has suggested his expected and minimal wage, $w_{e}$ and $w_{\min }$ respectively. We would like not to break funds $F$ with high necessity, of e.g. $h=0.8$ or $h=0.9$. One easily concludes from Figure 5 that this constraint is equivalent to:

$\frac{\sum x_{i} w_{e i}-F}{\sum x_{i}\left(w_{e i}-w_{\min i}\right)} \leq 1-h$

Other restrictions are possible, namely if we want to impose a minimal mark value in the certain job group, e.g. average computer skills among marketing assistants should be at least $M$. Since we observe all the marks as possibilistic distribution functions, we can pose this requirement differently, namely, we could demand that the minimal average computer skill is necessarily greater than $\mathrm{M}$, where we use high necessity measure of e.g. $h=0.8$ or $h=0.9$, as presented in Figure 6 . The set of restrictions is given by:

$$
\frac{M-\sum a_{i} x_{i}}{\sum a_{i} x_{i}} \leq 1-h
$$




\section{Results and Discussion}

Numerical example is provided in this section. Data from 30 applicants were collected, and only the marketing sector has been covered. Data can be found in Appendix $1^{2}$. In addition, applicants were asked to suggest their salary in terms of expected and minimum value. Values of salaries are given in Appendix 2. This group was tested for education levels, contacts, experience, leadership skills, organizational, computer secretarial, and communicational skills, as well as dependability. Not all skills are necessary for each position, namely: VP Marketing (up to two people) are tested for experience, contacts, education and leadership. Marketing assistants (MA, up to three) for organization, computer skills and education, Customer service representatives (CSR, up to four) for education, computer, secretarial and communicational skills. Finally, Shipping clerks (SC, up to five) were tested for dependability, organizational and computer skills. Objective function was to maximize the total manpower of future employees.

Results without limited funds are presented in Table 1. Results include restrictions imposed on VPs to have an average score of at least 20. For MAs for having an average mark on education and organization at least 8 , on CSRs to have average communicational skills at least 2.5.

Table 1

Optimal choice of applicants, necessity coefficient 0.8 . Unlimited funds

\begin{tabular}{|l|l|l|}
\hline Position & Ordinal number of the applicant & Costs \\
\hline VP & 13,23 & $185-190$ \\
\hline MA & $7,12,22$ & $285-295$ \\
\hline CSR & $4,9,26,30$ & $267-280$ \\
\hline SC & $8,15,16,21,29$ & $192-207$ \\
\hline
\end{tabular}

Total human capital equals 426.5. Total costs up to 972.

However, if the funds are decreased to 600 (in thousands of US dollars per annum) we observe the results in Table 2:

Table 2

Optimal choice of applicants, necessity coefficient 0.8 .Funds limited to 600

\begin{tabular}{|l|l|l|}
\hline Position & Ordinal number of the applicant & Costs \\
\hline VP & 7,12 & $195-200$ \\
\hline MA & $4,8,16$ & $100-108$ \\
\hline CSR & $6,11,15,25$ & $138-150$ \\
\hline SC & $9,14,20,27,29$ & $121-138$ \\
\hline
\end{tabular}

${ }^{2}$ Applicants are ordered from A.A. through B.D., and in tables in current chapter we used ordinal notation: A.A. is $1^{\text {st }}, \ldots$ B.D. is $30^{\text {th }}$. 
Total human capital is decreased to 355.4. Total costs up to 596. Major decrease in human capital is due to choosing applicants for CSR and SC positions with lower education levels, as well as low contacts and leadership skills. Even though these characteristics influence the total score, they are almost irrelevant for the positions in question, and chosen applicants show excellent results in characteristics needed for those positions (e.g. high computer and communicational skills).Further decrease in funding is presented in Table 3a and $3 b$, together with the change in desired necessity levels, from 0.8 to 0.95 .

Table 3a

Further decrease in funds, $\mathrm{F}=500, \mathrm{~h}=0.8$

\begin{tabular}{|l|l|l|}
\hline Position & Ordinal number of the applicant & Costs \\
\hline VP & 7,12 & $195-200$ \\
\hline MA & $4,8,16$ & $100-108$ \\
\hline CSR & $9,15,25,29$ & $97-106$ \\
\hline SC & $2,14,18,24,27$ & $76-88$ \\
\hline
\end{tabular}

Human capital is slightly decreased to 329.2 , while funds are at most 502, though crossing the limit by 2000 is unlikely, since necessity level is 0.8 . For extreme risk averse investors, Table $3 \mathrm{~b}$ exhibits the same funds, with necessity level 0.95 .

Table $3 b$

Further decrease in funds, $\mathrm{F}=500, \mathrm{~h}=0.95$

\begin{tabular}{|l|l|l|}
\hline Position & Ordinal number of the applicant & Costs \\
\hline VP & 7,30 & $187-195$ \\
\hline MA & $4,8,16$ & $100-108$ \\
\hline CSR & $9,15,25,29$ & $97-106$ \\
\hline SC & $2,14,18,24,27$ & $76-88$ \\
\hline
\end{tabular}

HC for this constellation equals 326.5. Maximal amount of money needed is almost certainly less than 497 . Huge savings are possible if focusing on applicants with lower levels of formal education, yet skillful.

\section{Conclusion}

We tried to present a possible application of hesitant fuzzy sets in the field of human resources allocation. Certain qualities of the applicants cannot be measured precisely, and an expert's opinion is needed, which as well may not be precise, or the expert might have doubts or hesitate to give a final mark. Hesitant fuzzy sets are designed to perfectly model these situations. We suggested possible objective functions, as well as an array of possible constraints. There were no restrictions on number of positions one applicant could apply. We tested the model on 30 applicants to Marketing sector of a company wanting to expand to 14 new positions. Results show that insignificant loss in total human potential, measured by sum of marks in all observed characteristics, can lead to substantial savings. 
Possible limitation might be the omission of interaction among cooperative individuals. When choosing a team of people it is relevant to measure a level of synergy within a team and test whether a team contributes more (or less) than the sum of independent performances of each team member. Surely it is possible to employ other mathematical methods in order to model synergy levels. However, the focus of this paper was on presenting a new method in decision making and mark giving, but this interesting topic will be fully investigated in our future work.

Appendix 1: List of 30 applicants and their grades in various characteristics

\begin{tabular}{|c|c|c|c|c|c|c|c|c|c|c|c|c|c|c|c|c|c|c|c|c|c|c|c|c|c|c|c|c|c|c|}
\hline & & & & & & & & & & & & & & & & & & & & & & & & & & & & & & \\
\hline & & 1,5 & 2,3 & 2,0 & 5,2 & 5,0 & 5,4 & & 4,4 & 4,2 & 3,2 & 5,2 & 7,2 & 2,4 & 3,1 & 3,2 & 2,4 & 3,2 & 2,4 & 4,4 & 5,3 & 4,3 & \begin{tabular}{|l|l}
6,6 \\
\end{tabular} & 3,2 & 2,3 & 4,4 & 3,2 & 4,3 & & \\
\hline & & & 2,2 & 2,0 & 5,1 & 5,0 & 5,2 & & 4,2 & 4,1 & 3,1 & 5,1 & 7,1 & 2,3 & 3,0 & 3,1 & 2,2 & 3,1 & 2,2 & 4,3 & 5,2 & \begin{tabular}{c|}
, 2 \\
\end{tabular} & 6,4 & 3,1 & 2,2 & 4,3 & 3,1 & 4,2 & 3, & 5,4 \\
\hline & & 1,3 & 2,1 & 2,0 & 5,0 & 5,0 & 5,0 & & 4 & & & 5,1 & 7,1 & 2,2 & 2,9 & & & 3 & 2 & 4,3 & 5,1 & 4,2 & 6,2 & 3,1 & 2,1 & 4,2 & 3,1 & 4,2 & 3,2 & 5,4 \\
\hline & & 1,2 & & 2,0 & 4,9 & 5,0 & 4,8 & & 3,8 & 3,9 & 2, & 5,0 & 7,0 & 2,1 & 2,8 & 2,9 & 1,8 & 2,9 & 1,8 & 4,2 & & 4,1 & & & 2 & 4,1 & & 4,1 & 3, & 5,3 \\
\hline & 2,5 & 2,3 & 3,5 & 3,5 & 5,2 & 5,2 & 52 & 3,4 & 4,3 & 4,8 & 3,9 & \begin{tabular}{l|l}
5,9 \\
\end{tabular} & 6,8 & 3,3 & 3,6 & 3,8 & 2,7 & 3,3 & 3,0 & 4,4 & 5,5 & 5,3 & 6,2 & 3,2 & 3,3 & 5,2 & 3,5 & 4,7 & 3,8 & \\
\hline 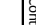 & 2,4 & 2,2 & 3,4 & 3,4 & 5,0 & 5,1 & 6,0 & 3 & 4,2 & 4,6 & 3,8 & 5,8 & 6,7 & 3,2 & 3,5 & 3,7 & & 3,2 & 3,0 & 4,3 & 5,5 & 5,2 & 6, & 3,2 & 3,2 & 5,1 & 3,5 & 4,6 & 3,7 & 5,5 \\
\hline & 2,4 & 2,2 & 3,4 & 3,4 & 4,8 & 5,1 & 68 & & 4,1 & 4,4 & 3,8 & 5,7 & 5,6 & & 3,5 & 3,6 & 2,6 & 3,2 & 3,0 & 4,2 & 5,5 & 52 & 6 & 3,2 & $\overline{3,2}$ & 5,1 & 3,5 & 4,5 & 3,7 & \\
\hline & 2,3 & 2,1 & 3,3 & 3,3 & 4,6 & 5,0 & 5,6 & 2, & 4,0 & 4,2 & 3,7 & 5,6 & 6,5 & 3,1 & 3,4 & 3,5 & 2,5 & 3,1 & 3,0 & 4,1 & 5,5 & 5,1 & 6,0 & 3,2 & 3,1 & 5,0 & 3,5 & 4,4 & 3,6 & 5,3 \\
\hline & 2,1 & 1,8 & 4,0 & \begin{tabular}{|l|l}
3,7 \\
\end{tabular} & 6,2 & 5,7 & $\overline{7,2}$ & & 3,8 & 5,8 & 3,5 & 6,0 & 7,5 & 3,5 & 2,1 & 2,0 & 1,9 & 1,7 & 3,3 & 3,2 & 5,2 & 5,5 & 7,3 & 1,5 & 3,0 & & 3,2 & 5,0 & 2,1 & \\
\hline & 2,0 & 1,7 & 4,0 & 3,6 & 6,1 & 5,5 & 7,1 & $2, c$ & 3,7 & 5,6 & 3,5 & 6,0 & 7,5 & 3,4 & 2,0 & 2,0 & 1,8 & \begin{tabular}{ll|}
1,6 \\
\end{tabular} & 3,2 & 3,1 & 5,1 & 5,5 & \begin{tabular}{|l|l}
7,2 \\
\end{tabular} & 1,4 & 3,0 & 5,0 & 3,1 & 5,0 & $2, c$ & 4,0 \\
\hline & 2,0 & & 4,0 & 3,6 & 6,0 & 5,3 & 7,1 & 2, & 3,6 & 5,4 & 3,5 & 6,0 & 7,5 & 3,4 & 1,9 & 2,0 & 1,7 & 1,5 & 3,2 & 3,0 & 5,1 & 5,5 & 7,2 & 1,3 & 3,0 & 5,0 & 3,0 & 5,0 & 2,6 & \\
\hline & 1,9 & 1,5 & 4,0 & 3,5 & $5,9\}$ & 5,1 & 7,0 & 2,6 & 3,5 & 5,22 & 3,5 & 6,00 & 7,5 & 3,3 & $1,8 \mid$ & 2,0 & 1,6 & 1,4 & 3,1 & 2,99 & 5,0 & 5,5 & 7,1 & 1,2 & 3,0 & 5,0 & 2,9 & 5,0 & 1,9 & 3,9 \\
\hline & 2,8 & 2,8 & 4,1 & \begin{tabular}{|l|l}
4,3 \\
\end{tabular} & 5,2 & 5,3 & 6,5 & 3,7 & 4,2 & 5,1 & 4,3 & 6,3 & 6,6 & 3,7 & 3,8 & 4,2 & 2,8 & 3,3 & 3,2 & 4,3 & 5,6 & 5,7 & 6,0 & 3,3 & 3,8 & & 3,6 & 4,8 & 4,0 & \\
\hline & 2,7 & 2,7 & & 4,2 & 5,1 & 5,2, & 6,5 & & 4,1 & & 4,2 & 6,22 & 6,4 & & 3,7 & & 2,7 & 3,2 & 3,1 & 4,2, & 5,5 & 5,5 & & 3,22 & 3,7 & 5,4 & 3,4 & $4,7\}$ & & 5,5 \\
\hline & 2,6 & 2,6 & & 4,1 & 5,1 & 5,1 & $\begin{array}{l}6,5 \\
\end{array}$ & 3,3 & 4,1 & 5 & 4,1 & 6,2 & 6,2 & 3,3 & 3,7 & & 2,6 & 3,2 & 3,1 & 4,1 & 5,4 & 5,3 & & 3,2 & 3,6 & 5,4 & 3,2 & 4,7 & & 5,5 \\
\hline & 2,5 & 2,5 & & 4,0 & 5,0 & 5,0 & 6,5 & 3,1 & 4 & 4,9 & & 6,1 & 60 & & \begin{tabular}{l|l|}
3,6 \\
\end{tabular} & 3,8 & 2,5 & 3,1 & 3 & & 5,3 & 5,1 & & 3,1 & 3,5 & 5,3 & & & & 5,4 \\
\hline & 1,3 & & 3,1 & 4,1 & 1,2 & 2,3 & 4,0 & & 1,4 & 2,2 & 3,1 & 4,7 & 2,0 & 2,3 & 3,3 & 4,3 & 1,2 & 2,1 & 1 & 2,4 & 3,3 & 4,4 & 1,2 & 2,1 & 3 & 4,2 & 1,5 & 2,2 & 3,4 & 4,2 \\
\hline & 1,2 & & & 4,0 & 1,1 & 2,2 & 4,0 & & 1,2 & 2,1 & & 4,6 & 2,0 & 2,2 & 3,2 & 4,2 & 1,1 & 2 & 1 & 2,3 & 3,2 & 4,2 & 1,1 & 2 & 3 & 4,1 & 1,5 & & 3,3 & 4,1 \\
\hline & 1,1 & & 2,9 & 4,0 & \begin{tabular}{|l}
1,1 \\
\end{tabular} & 2,2 & 4,0 & & 1 & 2,1 & & 4,6 & 2,0 & 2,2 & 3,1 & 4,1 & 1,1 & 2 & 1 & 2,2 & 3,1 & 4 & \begin{tabular}{|l|}
1,1 \\
\end{tabular} & 2 & 3 & 4,1 & 1,5 & 2,1 & 3,2 & 4,1 \\
\hline & & & 2,8 & 3,9 & 1,0 & 2,1 & 4,0 & & 0,8 & & 2,9 & 4,5 & 2,0 & 2,1 & 3,0 & & & 1,9 & 1 & 2,1 & & 3,8 & & 1,9 & & & 1,5 & & 3,1 & \\
\hline & 1,1 & 2,1 & 2,9 & 4,1 & 0,9 & 2,1 & 3,1 & & 1,1 & 2 & 3,2 & 4,5 & \begin{tabular}{ll|}
1,0 \\
\end{tabular} & 2,2 & 3,2 & 4,2 & 1,3 & 2,1 & 1,2 & 2,3 & 3,1 & 4,4 & \begin{tabular}{|l|l}
1,1 \\
\end{tabular} & 2,1 & 3,2 & 4 & 1,4 & 2,3 & 3,2 & 4,1 \\
\hline 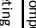 & & & 2,8 & 4,0 & 0,8 & 2,0 & 3,0 & & 1 & & 3,1 & 4,5 & 1,0 & 2, & $\begin{array}{ll}3,1 \\
\end{array}$ & 4,1 & 1,2 & 2 & 1,1 & 2,2 & & 4,3 & & 2 & 3,1 & & 1,3 & & & \\
\hline & & & 2,7 & 4,0 & 0,8 & 2,0 & 3,0 & & 1 & 2 & $\begin{array}{l}3,1 \\
\end{array}$ & 4,5 & 1,0 & 2,1 & 3,1 & 4,1 & 1,1 & 2 & $\begin{array}{ll}1,1 \\
\end{array}$ & 2,1 & & 4,2 & & 2 & 3 & 4 & 1,2 & 2,2 & 3,1 & \\
\hline & 0,9 & 1,9 & 2,6 & 3,9 & 0,7 & 1,9 & 2,9 & & 0,9 & & & 4,5 & 1,0 & 2,0 & 3,0 & & & $\begin{array}{l}1,9 \\
\end{array}$ & 1 & 2 & 2,9 & 4,1 & \begin{tabular}{|l|l}
0,9 \\
\end{tabular} & 1,9 & 2,9 & & 1,1 & & & 3,9 \\
\hline & 2,1 & 1,8 & & $\begin{array}{l}3,7 \\
3\end{array}$ & 6,2 & 5,7 & 7,2 & & 3,8 & 5,8 & 3,5 & 6,0 & 7,5 & 3,5 & 2,1 & 2 & 1,9 & 1,7 & \begin{tabular}{l|}
3,3 \\
\end{tabular} & 3,2 & 5,2 & 5,5 & 7,3 & 1,5 & 3 & & 3,2 & & 2,1 & 4,1 \\
\hline & & 1,7 & & 3,6 & 6,1 & 5,5 & 7,1 & & 3,7 & 5,6 & \begin{tabular}{|l|}
3,5 \\
\end{tabular} & & 7,5 & 3,4 & & & 1,8 & 1,6 & 3,2 & 3,1 & 5,1 & & 7,2 & 1,4 & 3 & & 3,1 & 5 & & 4 \\
\hline & & 1,6 & & 3,6 & & 5,3 & 7,1 & & 3,6 & 5,4 & 3,5 & 6 & 7,5 & 3,4 & 1,9 & 2 & 1,7 & 1,5 & 3,2 & & 5,1 & $\begin{array}{l}5,5 \\
\end{array}$ & \begin{tabular}{|l}
7,2 \\
\end{tabular} & 1,3 & & & & & & \\
\hline & 1,9 & 1,5 & & 3,5 & 5,9 & 5,1 & & & 3,5 & 5,2 & 3,5 & 6 & 7,5 & 3,3 & 1,8 & & 1,6 & 1,4 & 3,1 & 2,9 & & 5,5 & \begin{tabular}{|l|l}
7,1 \\
\end{tabular} & 1,2 & 3 & & 2,9 & 5 & 1,9 & 3,9 \\
\hline & 1,1 & 2,1 & 2,9 & \begin{tabular}{|l|l} 
\\
\end{tabular} & \begin{tabular}{|l|l}
0,9 \\
\end{tabular} & 2,1 & 3,1 & & 1,1 & & 3,2 & 4,5 & 1 & $\overline{2,2}$ & 3,2 & 4,2 & 1,3 & 2,1 & 1,2 & 2,3 & 3,1 & 4,4 & \begin{tabular}{|l|}
1,1 \\
\end{tabular} & 2,1 & 3,2 & & 1,4 & 2,3 & 3,2 & 4,1 \\
\hline 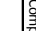 & 1 & & 2,8 & & \begin{tabular}{|c|}
0,8 \\
\end{tabular} & & & & 1 & 2 & 3,1 & 4,5 & 1 & 2,1 & 3,1 & 4,1 & 1,2 & 2 & 1,1 & 2,2 & & 4,3 & & 2 & 3,1 & & 1,3 & 2,2 & 3,1 & \\
\hline & & 2 & 2,7 & & , & & & & 1 & & 3,1 & 4,5 & 1 & 2,1 & 3,1 & 4,1 & 1,1 & & \begin{tabular}{l|l|}
1,1 \\
\end{tabular} & 2,1 & & 4,2 & & 2 & & & 1,2 & 2,2 & 3,1 & 4 \\
\hline & 0,9 & 1,9 & $\begin{array}{l}2,6 \\
\end{array}$ & 3,9 & 0,7 & 1,9 & 2,9 & & $\begin{array}{l}0,9 \\
\end{array}$ & & & $\begin{array}{l}4,5 \\
4\end{array}$ & 1 & 2 & 3 & 4 & 1 & 1,9 & 1 & 2 & 2,9 & 4,1 & \begin{tabular}{|l|l}
0,9 \\
\end{tabular} & 1,9 & 2,9 & & 1,1 & 2,1 & & 3,9 \\
\hline & 2,1 & 1,8 & & 3,7 & 6,2 & $\begin{array}{l}, 7 \\
\end{array}$ & 7, & & $\begin{array}{l}3,8 \\
\end{array}$ & \begin{tabular}{|c|}
5,8 \\
\end{tabular} & 3, & 6 & \begin{tabular}{r|}
7,5 \\
\end{tabular} & 3,5 & 2,1 & & 1,9 & 1,7 & \begin{tabular}{l|l}
3,3 \\
\end{tabular} & 3,2 & 5,2 & \begin{tabular}{c|}
5,5 \\
\end{tabular} & \begin{tabular}{|l|l}
7,3 \\
\end{tabular} & $\begin{array}{l}, 5 \\
\end{array}$ & & & 3,2 & - & 2,1 & 4,1 \\
\hline & & 1,7 & & 3,6 & 6,1 & 5,5 & 7,1 & & 3,7 & 5,6 & 3,5 & 6 & 7,5 & 3,4 & & 2 & 1,8 & \begin{tabular}{l|l}
1,6 \\
\end{tabular} & \begin{tabular}{l|l}
3,2 \\
\end{tabular} & 3,1 & 5,1 & \begin{tabular}{l|l}
5,5 \\
\end{tabular} & 7,2 & 1,4 & & & 3,1 & 5 & & \\
\hline & 2 & 1,6 & 4 & 3,6 & & 5,3 & $\overline{7,1}$ & & $\begin{array}{l}3,6 \\
\end{array}$ & 5,4 & 3 & 6 & $\begin{array}{r}7,5 \\
\end{array}$ & 3 & $\begin{array}{l}1,9 \\
\end{array}$ & & 1,7 & 1,5 & \begin{tabular}{l|l}
3,2 \\
\end{tabular} & & 5,1 & \begin{tabular}{l|}
5,5 \\
5
\end{tabular} & \begin{tabular}{|l|l}
7,2 \\
\end{tabular} & 1,3 & & & & 5 & & \\
\hline & 1,9 & 1,5 & & 3,5 & 5,9 & 5,1 & & & 3,5 & 5,2 & 3,5 & 6 & 7,5 & 3,3 & \begin{tabular}{|c|}
1,8 \\
\end{tabular} & 2 & 1,6 & \begin{tabular}{ll|}
1,4 \\
\end{tabular} & 3,1 & 2,9 & & \begin{tabular}{l|l}
5,5 \\
\end{tabular} & \begin{tabular}{|l|l}
7,1 \\
\end{tabular} & 1,2 & 3 & 5 & 2,9 & 5 & 1,9 & 3,9 \\
\hline & 1,5 & 2,0 & 3,3 & 4,0 & \begin{tabular}{|l|}
2,8 \\
\end{tabular} & $\begin{array}{l}3,4 \\
3\end{array}$ & 4,8 & 3, & $\begin{array}{l}6,3 \\
\end{array}$ & $\begin{array}{l}3,3 \\
3\end{array}$ & 3,3 & 5,1 & 3,5 & 2,7 & \begin{tabular}{|l|}
2,9 \\
\end{tabular} & 3,5 & $\begin{array}{l}1,5 \\
\end{array}$ & 2,0 & \begin{tabular}{l|l}
1,8 \\
\end{tabular} & $\begin{array}{l}2,6 \\
\end{array}$ & 3,9 & $\begin{array}{ll}4,8 \\
\end{array}$ & \begin{tabular}{|l|l}
3,2 \\
\end{tabular} & 1,9 & 3,1 & 4,4 & 2,0 & 3,2 & 2,9 & 4,1 \\
\hline & 1,4 & 2,0 & 3,2 & 4,0 & 2,6 & 3,3 & 4,7 & 3,2 & 6,2 & 3,2 & 3,2 & 5,0 & 3,4 & 2,6 & 2,8 & 3,5 & 1,4 & 2,0 & \begin{tabular}{|l|}
1,7 \\
\end{tabular} & 2,5 & 3,8 & \begin{tabular}{|l|l|}
4,7 \\
\end{tabular} & 3,1 & 1,8 & 3,0 & 4,3 & 2,0 & 3,1 & 2,8 & 4,0 \\
\hline & 1,4 & 2,0 & 3,2 & 4,0 & 2,4 & 3,2 & 4,5 & 3,7 & \begin{tabular}{ll|}
6,1 \\
\end{tabular} & 3,1 & 3,1 & 5,0 & 3,2 & 2,6 & \begin{tabular}{|l|}
2,7 \\
\end{tabular} & 3,5 & 1,4 & 2,0 & \begin{tabular}{l|l}
1,6 \\
\end{tabular} & 2,5 & $\begin{array}{l}, 7,7 \\
\end{array}$ & $\begin{array}{ll}4,7 \\
\end{array}$ & \begin{tabular}{|l}
3,1 \\
\end{tabular} & $\begin{array}{l}1,8 \\
\end{array}$ & 3,0 & 4,2 & 2,0 & 3,1 & 2,7 & 4,0 \\
\hline & 1,3 & 2,0 & 3,1 & 4,0 & 2,2 & 3,1 & 4,4 & 3,1 & 6,0 & 3,0 & 3,0 & $\begin{array}{ll}4,9 \\
\end{array}$ & 3,1 & 2,5 & \begin{tabular}{|l|}
2,6 \\
\end{tabular} & \begin{tabular}{l|}
3,5 \\
\end{tabular} & 1,3 & 2,0 & \begin{tabular}{l|l}
1,5 \\
\end{tabular} & 2,4 & 3,6 & \begin{tabular}{ll|}
4,6 \\
\end{tabular} & \begin{tabular}{|l|l}
3,0 \\
\end{tabular} & $\begin{array}{ll}1,7 \\
\end{array}$ & 2,9 & 4,1 & 2,0 & 3,0 & 2,6 & 3,9 \\
\hline & 1,3 & 2,0 & 2,9 & 3,8 & 1,7 & 2,7 & 3,8 & 4,0 & 6,0 & 2,4 & 3,2 & 4,7 & 2,4 & 2,3 & \begin{tabular}{l|l}
3,2 \\
\end{tabular} & 4,1 & 1,5 & \begin{tabular}{|l|}
2,3 \\
\end{tabular} & \begin{tabular}{l|l}
1,3 \\
\end{tabular} & 2,7 & 3,5 & $\begin{array}{ll}4,4 \\
\end{array}$ & \begin{tabular}{|l|l}
2,1 \\
\end{tabular} & 2,3 & 3,0 & 4,1 & 1,7 & 2,6 & 3,3 & 4,4 \\
\hline & 1,2 & & 2,8 & 3,7 & 1,6 & 2,6 & 3,7 & & 6 & 2,3 & 3,1 & $\begin{array}{l}4,6 \\
\end{array}$ & 2,3 & 2,2 & 3,1 & & 1,4 & 2,2 & \begin{tabular}{l|}
1,2 \\
\end{tabular} & 2,6 & 3,4 & \begin{tabular}{|l|}
4,3 \\
\end{tabular} & & 2,2 & & & $\begin{array}{ll}1,6 \\
\end{array}$ & 2,5 & 3,2 & 4,3 \\
\hline & 1,2 & & 2,7 & 3,6 & 1,5 & 2,4 & 3,6 & & 6 & 2,3 & 3,1 & $\begin{array}{l}4,5 \\
\end{array}$ & 2,2 & 2,1 & & & 1,4 & \begin{tabular}{l|l}
2,1 \\
\end{tabular} & \begin{tabular}{l|l}
1,2 \\
\end{tabular} & 2,4 & $\begin{array}{l}3,3 \\
\end{array}$ & \begin{tabular}{|l|}
4,2 \\
\end{tabular} & & 2,1 & & & 1,4 & & & 4,1 \\
\hline & 1,1 & & 2,6 & 3,5 & 1,4 & \begin{tabular}{|l|}
2,3 \\
\end{tabular} & 3,5 & & 6 & 2,2 & & \begin{tabular}{l|l}
4,4 \\
\end{tabular} & 2,1 & & \begin{tabular}{l|l}
2,9 \\
\end{tabular} & 3,9 & $\begin{array}{ll}1,3 \\
\end{array}$ & 2 & \begin{tabular}{l|l}
1,1 \\
\end{tabular} & 2,3 & 3,2 & \begin{tabular}{l|l}
4,1 \\
\end{tabular} & 1,9 & 2 & & 3,9 & 1,3 & 2,4 & 3,1 & - \\
\hline & 1,55 & 1,8 & 2,6 & 3,05 & \begin{tabular}{|l|}
3,05 \\
\end{tabular} & 3,55 & 4,25 & & 2,75 & 3,1 & 3,22 & 4,85 & 4,1 & 2,3 & 3,15 & 3,7 & 1,85 & \begin{tabular}{|l|}
2,65 \\
\end{tabular} & \begin{tabular}{l|l}
1,8 \\
\end{tabular} & 3,35 & 4,2 & \begin{tabular}{l|l}
4,35 \\
\end{tabular} & \begin{tabular}{|l|l|}
3,85 \\
\end{tabular} & 2,65 & 2,75 & & 2,3 & & & 4,8 \\
\hline & 1,5 & 1,7 & 2,5 & 3 & 3 & 3,5 & 4,2 & & 2,7 & & 3,1 & \begin{tabular}{|l|l|}
4,8 \\
\end{tabular} & 4 & 2,2 & 3,1 & 3,6 & 1,8 & \begin{tabular}{|l|}
2,6 \\
\end{tabular} & \begin{tabular}{|l|}
1,7 \\
\end{tabular} & 3,3 & \begin{tabular}{|l|}
4,1 \\
\end{tabular} & 4,3 & \begin{tabular}{|l|}
3,8 \\
\end{tabular} & 2,6 & 2,7 & 4,1 & 2,2 & 3,2 & 3,2 & 4,7 \\
\hline & 1,5 & \begin{tabular}{ll|}
1,6 \\
\end{tabular} & 2,4 & & & 3,4 & 4,2 & & 2,6 & & & \begin{tabular}{|l|}
4,6 \\
\end{tabular} & 4 & 2,1 & 3,1 & 3,5 & \begin{tabular}{ll|}
1,6 \\
\end{tabular} & \begin{tabular}{l|}
2,5 \\
\end{tabular} & \begin{tabular}{l|l}
1,5 \\
\end{tabular} & 3,3 & & \begin{tabular}{l|l}
4,2 \\
\end{tabular} & \begin{tabular}{|l|l}
3,8 \\
\end{tabular} & 2,6 & 2,5 & & 2,1 & & 3,1 & 4,5 \\
\hline & 1,4 & 1,5 & 2,3 & 2,9 & 2,9 & 3,3 & 4,1 & & \begin{tabular}{l|}
2,5 \\
\end{tabular} & 2,9 & 2,9 & \begin{tabular}{|l|l|}
4,5 \\
\end{tabular} & 3,9 & 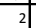 & 3 & 3,4 & 1,5 & 2,4 & 1,4 & 3,2 & 3,9 & \begin{tabular}{l|l}
4,1 \\
\end{tabular} & \begin{tabular}{|l|}
3,7 \\
\end{tabular} & 2,5 & 2,4 & 3,9 & & & & 4,4 \\
\hline & 1,3 & & 3,1 & 4,1 & \begin{tabular}{|l|}
1,2 \\
\end{tabular} & 2,3 & & & 14 & 2,2 & 3,1 & \begin{tabular}{|l|l|}
4,7 \\
\end{tabular} & & 2,3 & 3,3 & & 1,2 & 2,1 & \begin{tabular}{l|}
1 \\
\end{tabular} & 2,4 & 3,3 & \begin{tabular}{|l|}
4,4 \\
\end{tabular} & \begin{tabular}{|l|l}
1,2 \\
\end{tabular} & 2,1 & & 4,2 & 1,5 & & & 4,2 \\
\hline & 1,2 & 2 & 3 & 4 & 1,1 & \begin{tabular}{|l|}
2,2 \\
\end{tabular} & & 3 & 1,2 & 2,1 & 3 & 4,6 & 2 & 2,2 & 3,2 & 4,2 & 1,1 & 2 & 1 & 2,3 & \begin{tabular}{|l|}
3,2 \\
\end{tabular} & \begin{tabular}{|l|}
4,2 \\
\end{tabular} & \begin{tabular}{|l|}
1,1 \\
\end{tabular} & & 3 & \begin{tabular}{|l|}
4,1 \\
\end{tabular} & \begin{tabular}{|l|}
1,5 \\
\end{tabular} & 2,1 & \begin{tabular}{|l|}
3,3 \\
\end{tabular} & 4,1 \\
\hline & 1,1 & 2 & 2,9 & & 1,1 & 2,2 & & 3 & & 2,1 & & $\begin{array}{l}4,6 \\
\end{array}$ & 2 & 2,2 & 3,1 & 4,1 & 1,1 & & 1 & 2,2 & 3,1 & & \begin{tabular}{|l|l|}
1,1 \\
\end{tabular} & & & \begin{tabular}{l|l}
4,1 \\
\end{tabular} & 1,5 & 2,1 & & 4,1 \\
\hline & & 2 & \begin{tabular}{|l}
2,8 \\
\end{tabular} & \begin{tabular}{|l|l|}
3,9 \\
\end{tabular} & 1 & \begin{tabular}{|l|l|}
2,1 \\
\end{tabular} & & 3 & \begin{tabular}{|l|}
0,8 \\
\end{tabular} & 2 & 2,9 & \begin{tabular}{|l|}
4,5 \\
\end{tabular} & 2 & 2,1 & 3 & & 1 & \begin{tabular}{l|l}
1,9 \\
\end{tabular} & 1 & 2,1 & \begin{tabular}{|c|}
3 \\
\end{tabular} & \begin{tabular}{|c|}
3,8 \\
\end{tabular} & 1 & 1,9 & 3 & & 1,5 & 2 & 3,1 & 4 \\
\hline & 1,1 & 2,1 & 2,9 & \begin{tabular}{|l|l}
4,1 \\
\end{tabular} & \begin{tabular}{|l|}
0,9 \\
\end{tabular} & 2,1 & 3,1 & & 1,1 & & 3,2 & \begin{tabular}{|l|}
4,5 \\
\end{tabular} & 1 & 2,2 & 3,2 & 4,2 & 1,3 & 2,1 & \begin{tabular}{l|l}
1,2 \\
\end{tabular} & 2,3 & 3,1 & $\begin{array}{ll}4,4 \\
\end{array}$ & \begin{tabular}{|l|l}
1,1 \\
\end{tabular} & 2,1 & 3,2 & & 1,4 & & & 4,1 \\
\hline 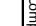 & & & 2,8 & 4 & \begin{tabular}{l|l}
0,8 \\
\end{tabular} & 2 & 3 & 5 & 1 & 2 & 3,1 & \begin{tabular}{|l|}
4,5 \\
\end{tabular} & 1 & 2,1 & 3,1 & \begin{tabular}{|l|}
4,1 \\
\end{tabular} & 1,2 & 2 & \begin{tabular}{|l|}
1,1 \\
\end{tabular} & 2,2 & 3 & \begin{tabular}{|l|}
4,3 \\
\end{tabular} & 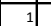 & 2 & 3,1 & & \begin{tabular}{|l|}
1,3 \\
\end{tabular} & 2,2 & 3,1 & \\
\hline & & & $2,7]$ & & \begin{tabular}{|l|}
0,8 \\
\end{tabular} & & & 5] & & & 3,1 & \begin{tabular}{|l|}
4,5 \\
\end{tabular} & 1 & 2,1 & 3,1 & \begin{tabular}{|l|}
4,1 \\
\end{tabular} & 1,1 & & \begin{tabular}{l|l}
1,1 \\
\end{tabular} & 2,1 & & \begin{tabular}{|l|}
4,2 \\
\end{tabular} & & & & & \begin{tabular}{|l|}
1,2 \\
\end{tabular} & & 3,1 & \\
\hline & & & & & & \begin{tabular}{|l|}
1,9 \\
\end{tabular} & & & \begin{tabular}{|l|}
0,9 \\
\end{tabular} & & & \begin{tabular}{|l|}
4,5 \\
\end{tabular} & 1 & & & & & \begin{tabular}{|l|}
1,9 \\
\end{tabular} & 1 & & 2,9 & & \begin{tabular}{|l|}
0,9 \\
\end{tabular} & & & & & & & 3,9 \\
\hline
\end{tabular}


Appendix 2: Expected and minimal salaries per annum (in thousands USD), per applicant

\begin{tabular}{|c|c|c|c|c|c|c|c|c|c|c|c|c|c|c|c|c|c|c|c|c|c|c|c|c|c|c|c|c|c|c|}
\hline oplica & 1 & 2 & 3 & 4 & 5 & 6 & 7 & 8 & 9 & 10 & 11 & 12 & 13 & 14 & 15 & 16 & 17 & 18 & 19 & 20 & 21 & 22 & 23 & 24 & 25 & 26 & 27) & 28 & 29 & \\
\hline $\exp$ & 15 & 15 & 41 & 55 & 60 & 65 & 100 & 20 & 40 & 60 & 42 & 100 & 100 & 18 & 21 & 43 & 15 & 15 & 17 & 40 & 100 & 95 & 90 & 16 & 22 & 90 & 17 & 55 & 23 & 95 \\
\hline $\min$ & 13 & 13 & 38 & 53 & 55 & 60 & 95 & 18 & 36 & 54 & 38 & 100 & 97 & 16 & 20 & 39 & 13 & 14 & 15 & 35 & 96 & 90 & 88 & 1 & 20 & 86 & 15 & 52 & 19 & \\
\hline
\end{tabular}

\section{References}

[1] Atanassov, K.; Gargov, G: Interval Valued Intuitionistic Fuzzy Sets, Fuzzy Sets and Systems, Vol. 3, No. 3, 1989, pp. 343-349

[2] Ballesteros-Pérez, P.; González-Cruz, C.; Fernández-Diego, M: Human Resource Allocation Management in Multiple Projects Using Sociometric Techniques, International Journal of Project Management, Vol. 30, No. 8, 2012, pp. 901-913

[3] Bellman, R. E.; Zadeh, L. A: Decision-Making in a Fuzzy Environment. Management Sci. Vol. 17, 1970, pp. 141-164

[4] Dubois, D.; Prade, H: Systems of Linear Fuzzy Constraints, Fuzzy Sets and Systems, Vol. 3, 1980, pp. 37-48

[5] Dubois, D: Linear Programming with Fuzzy Data, in: J. C. Bezdek (Ed.), Analysis of Fuzzy Information 3: Applications in Engineering and Science, CRC Press, Boca Raton, FL, 1987, pp. 241-263

[6] Filho, C. F. F. C.; Rocha, D. A. R.; Costa, M. G. F.; Pereira, W. C. A: Using Constraint Satisfaction Problem Approach to Solve Human Resource Allocation Problems in Cooperative Health Services, Expert Systems with Applications, Vol. 39, No. 1, 2012, pp. 385-394

[7] Inuiguchi, M.; Sakawa, M.; Kume, Y: The Usefulness of Possibilistic Programming in Production Planning Problems, Int. J. Prod. Economics, Vol. 33, 1994, pp. 45-52

[8] Inuiguchi, M.; Tanino, T.; Sakawa, M: Membership Function Elicitation in Possibilistic Programming Problems, Fuzzy Sets and Systems, Vol. 111, No. 1, 2000, pp. 29-45

[9] Klir, G.; Yuan: Fuzzy Sets and Fuzzy Logic: Theory and Applications, Prentice Hall PTR, 2005

[10] Lin, C-M; Gen, M: Multi-Criteria Human Resource Allocation for Solvingmultistage Combinatorial Optimization Problems Using Multiobjective Hybrid Genetic Algorithm, Expert Systems with Applications, Vol. 34, 2008, pp. 2480-2490

[11] Nagy, K.; Diveki, Sz.; Odry, P.; Sokola, M.; Vujicic, M: A Stochastic Approach to Fuzzy Control, Acta Polytechnica Hungarica, Journal of Applied Sciences, Vol. 9, No. 6, 2012, pp. 29-48

[12] Negoita, C. V.; Minoiu, S.; Stan, E: On Considering Imprecision in Dynamic Linear Programming. Economic Comput. Economic Cybernet. Stud. Res, Vol. 3, 1976, pp. 83-95 
[13] Osman, M. S.; Abo-Sinna, M. A.; Mousa, A. A: An Effectivegenetic Algorithm Approach to Multiobjective Resource Allocationproblems, Applied Mathematics and Computation, Vol. 163, 2005, pp. 755-768

[14] Portik, T.; Pokorádi, L: The Summarized Weighted Mean of Maxima Defuzzification and Its Application at the End of the Risk Assessment Process, Acta Polytechnica Hungarica, Vol. 11, No. 3, 2014, pp. 167-180

[15] Rezaei, P.; Rezaie, K.; Nazari-Shirkouhi, S.; Jamalizadeh Tajabadi, M. R: Application of Fuzzy Multi-Criteria Decision Making Analysis for Evaluating and Selecting the Best Location for Construction of Underground Dam, Acta Polytechnica Hungarica, Vol. 10, No. 7, 2013, pp. 187-205

[16] Rodríguez, R. M.; Martínez, L.; Herrera, F: A Group Decision Making Model Dealing with Comparative Linguistic Expressions Based on Hesitant Fuzzy Linguistic Term Sets, Information Sciences, Vol. 241, 2013, pp. 2842

[17] Rodríguez, R. M.; Martínez, L.; Herrera, F: Hesitant Fuzzy Linguistic Term Sets for Decision Making, IEEE Transactions on Fuzzy Systems, Vol. 20, No. 1, 2012, pp. 109-119

[18] Saaty, T. L: Decision Making with Dependence and Feedback: the Analytic Hierarchy Process, RWS Publications, 4922 Ellsworth Avenue, Pittsburgh PA 15213, 1996

[19] Saaty, T. L.; Vargas, L. G.; Dellmann, K: The Allocation of Intangible Resources: the Analytical Hierarchy Process and Linear Programming, Socio-Economic Planning Sciences, Vol. 37, 2003, pp. 169-184

[20] Saaty, T. L.; Peniwatib, K.; Shanga, J. S: The Analytic Hierarchy Process and Human Resource Allocation: Halfthe Story, Mathematical and Computer Modelling, Vol. 46, 2007, pp. 1041-1053

[21] Silva, L. C.; Costa, A. P. C. S: Decision Model for Allocating Human Resources in Information System Projects, International Journal of Project Management, Vol. 31, No. 1, 2013, pp. 100-108

[22] Takács, M: Multilevel Fuzzy Approach to the Risk and Disaster Management, Acta Polytechnica Hungarica, Journal of Applied Sciences, Vol. 7, No. 4, 2010, pp. 91-102

[23] Torra, V: Hesitant Fuzzy Sets, International Journal of Intelligent Systems, Vol. 25, 2010, pp. 529-539

[24] Zemova, B.; Talasova, J: Fuzzy Sets in HR Management, Acta Polytechnica Hungarica, Journal of Applied Sciences, Vol. 8, No. 3, 2011, pp. 113-124

[25] Xia, M.; Xu, Z: Hesitant Fuzzy Information Aggregation in Decision Making, International Journal of Approximate Reasoning, Vol. 52, 2011, pp. $395-407$ 